\title{
The TRAFI/C5 region is a risk factor for polyarthritis in juvenile idiopathic arthritis
}

\author{
HM Albers*1, FAS Kurreeman ${ }^{1}$, JJ Houwing-Duistermaat ${ }^{1}$, DMC Brinkman ${ }^{1}$, \\ SSM Kamphuis², HJ Girschick ${ }^{3}$, C Wouters ${ }^{4}$, MAJ van Rossum ${ }^{5}$, W Verduyn ${ }^{1}$, \\ REM Toes ${ }^{1}$, TWJ Huizinga ${ }^{1}$, MW Schilham ${ }^{1}$ and R ten Cate ${ }^{1}$
}

Address: ${ }^{1}$ Leiden University Medical Center, Leiden, Netherlands, ${ }^{2}$ Erasmus Medical Center - Sophia Children's Hospital, Rotterdam, Netherlands, ${ }^{3}$ University of Wuerzburg, Wuerzburg, Germany, ${ }^{4}$ University Hospital Gasthuisberg, Leuven, Belgium and ${ }^{5}$ Emma Children's Hospital AMC, Amsterdam, Netherlands

* Corresponding author

from $15^{\text {th }}$ Paediatric Rheumatology European Society (PreS) Congress

London, UK. 14-17 September 2008

Published: 15 September 2008

Pediatric Rheumatology 2008, 6(Suppl I):PII doi:I0.I I86/I546-0096-6-SI-PI I

This abstract is available from: http://www.ped-rheum.com/content/6/SI/PII

(c) 2008 Albers et al; licensee BioMed Central Ltd.

\section{Background}

Juvenile idiopathic arthritis (JIA) is a chronic disorder in which both genetic and environmental factors are involved. Recently we identified the TRAF1/C5 region (located on chromosome 9q33-34) as a risk factor for rheumatoid arthritis $(\mathrm{RA})\left(\mathrm{p}_{\text {combined }}=1.4 \times 10^{-8}\right)$ [1]. In the present study the association of the TRAF1/C5 region with the susceptibility to JIA was investigated.

\section{Methods}

A case-control association study was performed in 338 Caucasian JIA patients and 511 healthy individuals. We genotyped SNP rs 10818488 as a marker for the TRAF1/C5 region.

\section{Results}

The A-allele was associated with the susceptibility to Rheumatoid Factor (RF) negative polyarthritis with an $11 \%$ increase in allele frequency (OR 1.54, 95\% CI 1.09$2.18 ; \mathrm{p}=0.012$ ). This association was stronger when combining subtypes with a polyarticular phenotype (OR 1.46, 95\% CI 1.12-1.90; $\mathrm{p}=0.004$ ). In addition, we observed a trend towards an increase in A-allele frequency in patients with extended oligoarthritis versus persistent oligoarthritis ( $49 \%$ and $38 \%$ respectively); $\mathrm{p}=0.055$.

\section{Conclusion}

Apart from being a well replicated risk factor for RA, TRAF1/C5 also appears to be a risk factor for the RF negative polyarthritis subtype of JIA and, more generally, seems to be associated with subtypes of JIA characterized by a polyarticular course.

\section{References}

I. Kurreeman FA, Padyukov L, Marques RB, Schrodi SJ, Seddighzadeh M, Stoeken-Rijsbergen G, Helm-van Mil AH van der, Allaart CF, Verduyn W, Houwing-Duistermaat J, et al:: A candidate gene approach identifies the TRAFI/C5 region as a risk factor for rheumatoid arthritis. PLoS Med 2007, 4:e278. 